\title{
Risk, predictability and biomedical neo-pragmatism
}

Olaf Dammann (odammann@tuftsmedicalcenter.org)

Floating Hospital for Children at Tufts Medical Center, Boston, MA, USA

\section{Keywords}

Neo-pragmatism, Prediction, Risk factors

\section{Correspondence}

Olaf Dammann, Pediatric Clinical Research Center, Floating Hospital for Children at Tufts Medical

Center, 800 Washington St., Box 854, Boston,

MA 02111 , USA.

Tel: (617) 6360240 |

Fax: (617) 6363375

Email: odammann@tuftsmedicalcenter.org

Received

4 May 2009; accepted 5 May 2009.

DOI:10.1111/j.1651-2227.2009.01373.x

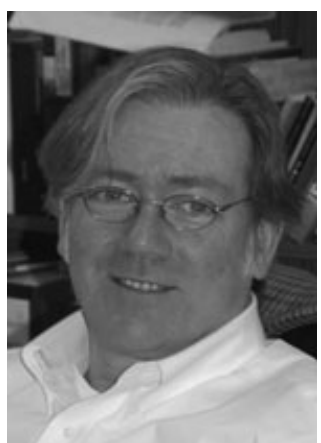

Singleton baby boy Lars is born at 25 weeks gestation. He weighs $523 \mathrm{~g}$ and his mother did not receive antenatal glucocorticoid. Although the online calculator http:// www.nichd.nih.gov/about/org/cdbpm/pp/prog_epbo/epbo _case.cfm (based on ref (1) predicts a 90\% chance of 'death or moderate to severe neurodevelopmental impairment', Lars survives just fine and makes it to high school age without any developmental problem whatsoever. He just happens to be that one out of ten.

Does not this remind you of those familiar stories of great grandfathers who smoked for their entire lives and lived to see their great grandchildren getting married? How can this be, with tobacco smoking being associated with a two to fourfold increased mortality risk, adjusted for social status (2)?

The educated reader will readily agree that I am confusing individual and population risk here. Maybe I also mingle inappropriately those general concepts that reach beyond the medical context, i.e. prediction in individuals and in populations? How are risk and prediction defined in the first place, and how understood?

Tricky issues, indeed. In what follows, I offer a few brief thoughts about these concepts, zooming in on the biomedical sciences context.

\section{RISK}

You can measure the baby's weight and length, and the number of days she spent in the hospital. You can also measure her blood concentration of C-reactive protein and her urinary output. But you cannot measure her risk of, say,

Article in the series A Different View are edited by Alan Leviton (alan.leviton@childrens.harvard.edu). developing cerebral palsy, however defined. Risk is a parameter, something beyond measurement.

Although immeasurable, the concept of risk is deeply entrenched in everyone's perception of the dangers (perceived or real) of everyday life (3). So is our desire to quantify it. Bankers crunch numbers, performing 'risk assessments' before breaking the deal. Business decisions are governed by 'risk-benefit ratios'. In biomedical research, risk-factor epidemiology (4) is deemed a black box by some (5) and defended by others (6).

Quantitative risk perception varies as widely as does the interpretation of likelihoods in general. While the "chance of showers' announced in the radio forecast might prompt one person to carry an umbrella all day, it might lead another not to consider this a worthwhile effort. Of course, it all depends on your definition of 'chance', which some might interpret as meaning 'highly likely', while others think 'close to zero'. Another nonlinguistic point here is: what is at stake? Would you travel to that remote corner of the world if the chance of acquiring the swine flu is 5\%? Maybe yes. Would you jump out of the airplane if you knew there was a 5\% chance the parachute might not open? Maybe not. Would you reject that null hypothesis if the chance of being wrong was 5\%? Absolutely! For more on the question, 'Why 5\%?', see reference (7).

Bottom line is, it is impossible to apply probabilities to individuals. It is what theoreticians might call a 'category error'. Miettinen pointedly asserts that 'risk is inherently a theoretical, nonempirical entity ... (that) refers to individuals (of a given kind)' (8) (emphasis Miettinen's). Just as one cannot equate laboratory rats and human patients, one cannot equate the incidence of an event in populations [what von Mises calls 'the collective' (9)] to the risk of this event in individuals. Yes, we do it all the time, by drawing a parallel, 
an inference. But sometimes, we need to be reminded that we might do this at the cost of making irrational decisions.

Yes, airplanes do indeed crash, albeit rarely. We all are very familiar with those nasty thoughts that linger in the back of our minds when our palms begin to sweat at takeoff. Want some numbers? When data were gathered from 3306 air line pilots, 66 crashes were documented in a total of 12.9 million flight hours (10). This translates into 22.3 years you have to be in the air 24/7 (current lingo for 'all the time') to experience one crash. In essence, if you fly during office hours only ( $8 \mathrm{~h}$ per day, 5 days a week) you will experience one crash in 93 years. Here is the point: sometimes, it is our inferences (and sometimes anxieties) that go wild, not our science.

\section{PREDICTABILITY}

Most scientific research aims at an improved understanding of the facts. One reason we want to understand better is to be able to predict whether a certain event will occur or whether some intervention will be successful or not. Indeed, most research is evaluated in a rather pragmatic way, by assessing to what extent its conclusions stand the test of time by allowing for successful predictions.

As I alluded in the section on risk above, predicting the future of individual life trajectories is usually based on probabilistic population estimates. The concepts underlying most prediction research reach far back into the philosophy of science - deep into the sticky mess of 'causation in an indeterministic world' (11).

The reason risk factor epidemiologists seek to identify risk factors of outcomes is to learn about the causal framework of such outcomes, which in turn enables them to prevent their occurrence. Thus, they often make assumptions that attribute causal powers to observed risk factors. This is just fine, but I happen to agree with David Savitz, that 'causal inference is just that - an inference by the interpreter of the data, not a product of the study or something that is found within the evidence generated by the study' [(12), p20].

This latter statement might be a surprise to those who strongly believe in the explanatory powers of (here: biomedical) research. Is not this exactly what research and science are supposed to provide, i.e. proof that smoking does cause lung cancer or that drug $\mathrm{X}$ does cure disease $\mathrm{Y}$ ?

Alas, was it that simple. Those who always thought this to be the case should brace themselves for yet another quote from Savitz: "The cliché that epidemiologic studies generate only measures of association, not causation is meaningless ... even experiments just generate measures of associations as well'. [(12), p21]. Wow!

A reviewer of one of my manuscripts made it clear that she/he had a problem with the statement that ' $x$ predicted $y$ ' in the context of odd ratios. The reviewer was convinced that 'this statement ... is not accurate. As discussed above, ... (the data) DO NOT indicate that $X$ predicts $Y$ in any clinically useful way. Increased odds and predictability are not synonymous' (emphasis hers/his). Some of this criticism revolved around this reviewer's desire to have predictive values in addition to odds ratios. Our counter-point is that as much as predictive values may seem intuitive, they are misleading, precisely because they offer the illusion of predictability! Instead, all they really do is give the percentage of $\mathrm{Y}$ among those with $\mathrm{X}$ - no comparison group, no adjustments made. I am inclined to say that instead of accepting such illusion of predictability, I would rather go with real associations.

\section{NEO-PRAGMATISM: A VERY DIFFERENT VIEW}

If all I have said above were true, would it not boil down to the notion that causation cannot be established, and in the same vein, that prediction cannot be achieved? Indeed, that is what I am trying to sell in this article as a view different from the perspective often taken by both clinicians and researchers alike: that absolute proof is possible outside formal logic, that clinical trials infallibly establish the efficacy of medical interventions, and that the perfect prediction of a patient's future is possible given enough valid information.

To the contrary, I believe that such thinking is absolutely (oops!) inadequate. It simply does not matter whether an observed link between some exposure and outcome is called 'causation' or 'association' (13). Similarly, it simply does not matter whether you say that 'smoking is associated with lung cancer' or 'smoking predicts lung cancer'. What does matter is that identifying, and then removing or reducing predictors from populations can improve the human condition. This neo-pragmatist position deliberately works towards an abandonment of appearance-reality distinctions, a replacement of notions of truth with notions of hope, and a clearer distinction between more useful and less useful ideas how to create a better future (14).

I know I am not alone (15). However, I am also aware that such neo-pragmatic views about causation and intervention inspired by an anti-dualist perspective might cause your eyebrows to rise. However, I still hold that finding perfect predictors of your favourite health outcome is an elusive goal. I invite all opponents of this view to speak up and offer their perspective.

Although perhaps a nice dream, it remains a dream. Survivors like healthy Lars, the 25 -weeker, and that chain smoking great grandfather, are not a miracle. They are just perfect examples of how complex and unpredictable natural developmental trajectories are. And now, I encourage all believers in predictability to wake up and face the challenges of the indeterministic world of biomedicine!

\section{References}

1. Tyson JE, Parikh NA, Langer J, Green C, Higgins RD. Intensive care for extreme prematurity - moving beyond gestational age. N Engl J Med 2008; 358: 1672-81.

2. Gruer L, Hart CL, Gordon DS, Watt GC. Effect of tobacco smoking on survival of men and women by social position: a 28 year cohort study. BMJ 2009; 338: b480. 
3. Ropeik D, Gray G. Risk - a practical guide for deciding what's really safe and what's really dangerous in the world around you. Boston, NY: Houghton Mifflin, 2002.

4. Perry IJ. Risk factor epidemiology. Lancet 1997; 350: 1256.

5. Skrabanek P. The emptiness of the black box. Epidemiology 1994; 5: 553-5.

6. Savitz DA. In defense of black box epidemiology. Epidemiology 1994; 5: 550-2.

7. Gauvreau K, Pagano M. Why 5\%? Nutrition 1994; 10: 93-4.

8. Miettinen OS. Theoretical epidemiology. New York, NY: John Wiley \& Sons, 1985

9. von Mises R. Probability, statistics, and truth. New York, NY: Dover, 1981 (1957).

10. Li G, Baker SP, Grabowski JG, Qiang Y, McCarthy ML, Rebok GW. Age, flight experience, and risk of crash involvement in a cohort of professional pilots. Am J Epidemiol 2003; 157 : 874-80.

11. Dowe P, Noordhof P. Cause and chance. London/New York: Routledge, 2004.

12. Savitz DA. Interpreting epidemiologic evidence. Oxford: Oxford University Press, 2003.

13. Dammann O, Leviton A. Perinatal brain damage causation. Dev Neurosci 2007; 29: 280-8.

14. Rorty R. Philosophy and social hope. London; New York: Penguin, 1999.

15. Weed DL. Precaution, prevention, and public health ethics. J Med Philos 2004; 29: 313-32. 